\title{
World Health Organization reform languishes
}

$\mathrm{R}$ eforms to financing, governance and priority-setting were once again topics of debate at the recent meeting of the executive board of the World Health Organization (WHO), but some observers of the global health giant would like to see all the discussion accompanied by a little decision-making.

"The reform process and how it is moving forward has been quite slow and a little bit disappointing," says Dr. Remco van de Pas, who heads the Human Resources for Health project at the Wemos Foundation, a nonprofit health advocacy organization based in Amsterdam, The Netherlands. "There was already a special EB [executive board] meeting on the reforms, but quite little steps have been taken at the moment. However, in one sense I am satisfied, because, to take this process seriously, you need to have some time for democratic decision-making."

Budget and staffing cuts at WHO has prompted considerable debate of late, compelling the organization to narrow its focus. Some health experts claim these reforms are long overdue and that, with the rise of myriad other health organizations since the WHO was formed in 1948, cutting certain programs would do little harm to the overall global health landscape (www .cmaj.ca/lookup/doi/10.1503/cmaj.109 -3933). WHO has stated that it will concentrate its efforts in five core areas: health development, health security, strengthening health systems and institutions, generating evidence on health trends and determinants, and convening for better health (www.who.int/media centre/news/notes/2011/eb_20111104 /en/index.html).

At a special meeting to discuss potential reforms, held in November 2011, the executive board - which consists of 34 member states that represent the 194 member states in the organization's governing body, the World Health Assembly — lent its support to proposals from member states and the

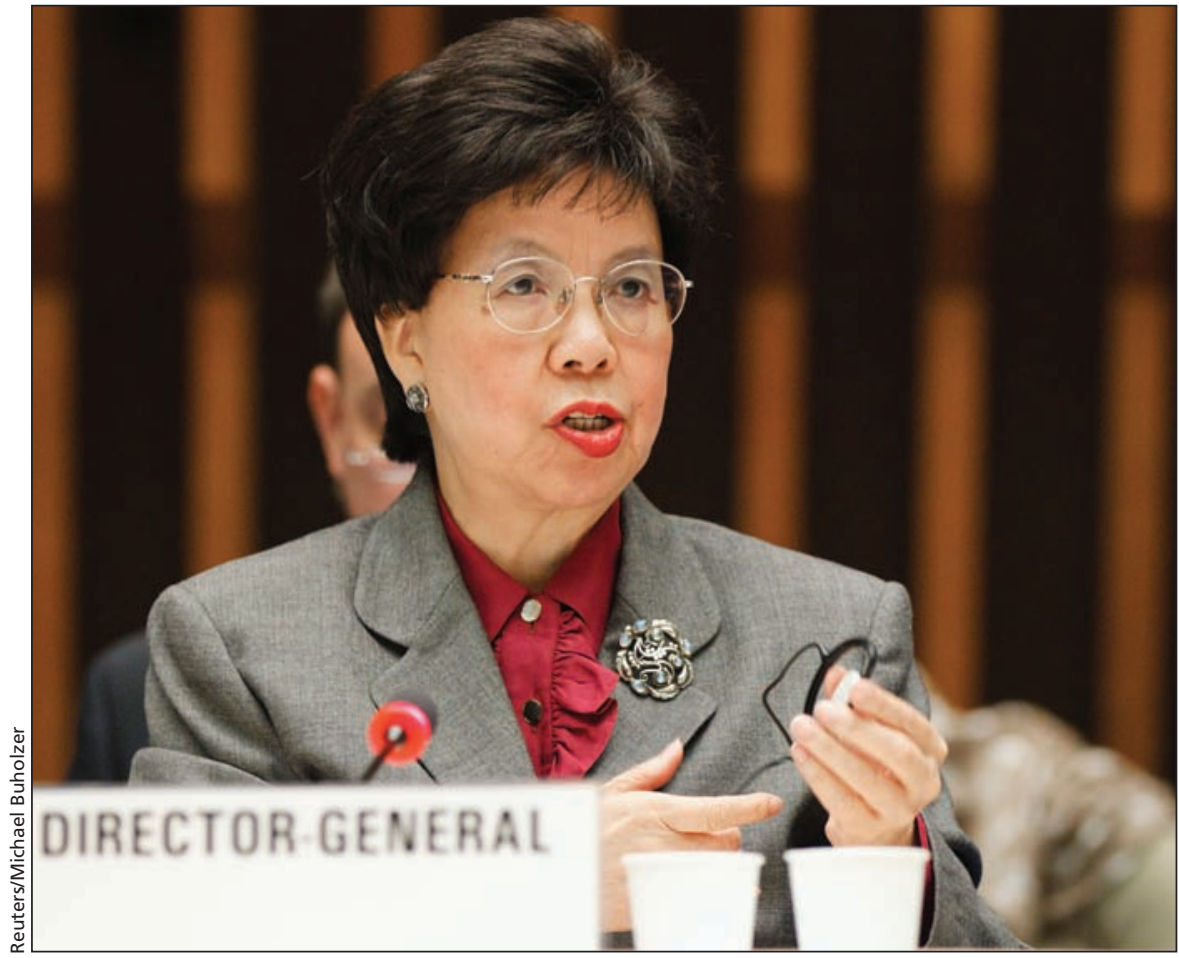

Dr. Margaret Chan, who has been nominated to serve a second term at the helm of the World Health Organization, delivers a speech at the executive board's meeting in Geneva, Switzerland.

director-general to improve financing and governance, to facilitate communication across WHO and to increase transparency and accountability (www .cmaj.ca/lookup/doi/10.1503/cmaj.109 -4067). At the 130th session of the executive board, held Jan. 16-23, discussions focused on three main areas: priority-setting for the organization; financing, management and evaluation; and internal governance and relations with external health stakeholders.

Engaging other stakeholders seems to be a particularly contentious topic among WHO member states, says van de Pas. According to some international health experts, WHO has in recent decades been outpaced by other players in global health, such as the World Bank and the Bill and Melinda Gates Foundation. At the executive board meeting, it was decided WHO should prepare a more detailed proposal on engaging external parties for the World
Health Assembly 2012, the 65th gathering of all member states, set for May 21-26 in Geneva, Switzerland.

"That is one of the most thorny issues, how to engage with other stakeholders," says van de Pas. "That is still on the table. Some member states would really like to engage more with both NGOs [nongovernmental organizations] and private sector foundations, whereas others are more hesitant."

One of those stakeholders, Médecins Sans Frontières (MSF), welcomed the review but noted that "there are no timelines for delivery," as Michelle Childs, policy and advocacy director of MSF's Campaign for Access to Essential Medicines, stated in an address to the executive board (www.msfaccess.org/sites /default/files/MSF_assets/Access/Docs /ACCESS_Statement_130EB_WHO reform_ENG_2012.pdf).

Reforms to WHO's financing have also generated considerable debate. Only 
$25 \%$ of the organization's budget comes from membership fees, with the rest coming from voluntary donations which, most of the time, are earmarked by the donors for particular causes. This leaves little flexibility for WHO to allocate resources according to global priorities. To address this problem, the executive board is considering a proposal to hold joint discussions with all donor nations.

"The idea is to look at a more transparent way by bringing everyone together in a collective process to create a sense of responsibility for making sure the budget is used properly," says Dr. Andrew Cassels, director of strategy in WHO's office of the director-general. "It was discussed in more detail [at the executive board meeting] but there are still questions being asked, and it will come up again.'

Progress in this area, as well as on the topic of priority-setting, made for a productive meeting of the executive board, says Cassels. "Priority-setting is the toughest part, deciding where we should put our energies. We have proposed that they [member states] develop criteria for setting priorities," says Cas- sels. "The net result [of the executive board meeting] is progress in some areas and an increasing recognition that the different components of the reform will work at different speeds. The priority-setting is the most important and we at least have agreed upon a process to getting there, so there is some progress there. The principle of getting a more transparent and collective approach to financing is also moving quite well." Roger Collier, CMAJ

CMAJ 2012. DOI:10.1503/cmaj.109-4111 